\title{
Nonalcoholic Fatty Liver Disease, Carotid Intima-Media Thickness and Lipid Profile in Epileptic Children
}

\author{
Mahsa Ghajarzadeha, e, Soheila Borji ${ }^{\mathrm{b}}$, Sarvenaz Pourjabbarc, \\ Mehdi Mohammadifar ${ }^{\mathrm{b}}$, Mahmoud Reza Ashrafi ${ }^{\mathrm{d}}$
}

\begin{abstract}
Background: Sodium valporate and carbamazepine are among frequent medications utilized for seizure control in children. Several adverse effects such as fatty liver disease, lipid profile changes and increased Intima-Media Thickness (IMT) were reported among cases who were treated with these medications.
\end{abstract}

Methods: Here we assessed 38 children (under 18) who were treated by sodium valporate and carbamazepine for at least six months for developing adverse effects including fatty liver disease, lipid profile changes and increased IMT. Cases who were treated with two or more antiepileptic-drugs or treated less than six months with each of drugs were excluded. Fasting venous blood sample drawn andradiologic evaluation of liver and both carotid arteries by two independent individuals performed.

Results: We found fatty liver disease in five patients who were treated with sodium valporate and lower White Blood Cell (WBC) count in carbamazepine group. Lipid profiles and IMT of both carotid arteries were not significantly different between groups.

Conclusions: Children who are treated with sodium valproate would be better to be carefully assessed by sonographic modalities for developing fatty liver as an adverse effect of the drug.

Manuscript accepted for publication August 12, 2011

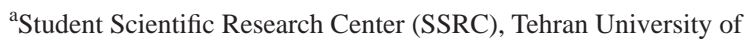
Medical Sciences, TUMS, Iran

${ }^{\mathrm{b}}$ Radiology,Medical Imaging Center, Advanced Diagnostic and Interventional Radiology Research Center (ADIR), Imam Khomeini Hospital,Tehran University of Medical Sciences, Iran

${ }^{\mathrm{c}}$ Tehran University of Medical Sciences, TUMS, Iran

${ }^{\mathrm{d}}$ Tehran University of Medical Sciences, Children Medical Center, TUMS, Iran

${ }^{\mathrm{e}}$ Corresponding author: Mahsa Ghajarzadeh, No 45, 32th Street, Gisha Avenue, Tehran, Iran. Email: mahsa_blue719@yahoo.com

doi:10.4021/jnr40w
Keywords: Seizure; Children; Fatty liver; IMT; Lipid profile

\section{Introduction}

Seizure is a chronic neurologic condition which makes a lot of troubles for children and their families. Seizure control with suitable drugs is critical to achieve seizure-free condition during treatment and after treatment withdrawal. Sodium valporate and carbamazepine are among frequent medications utilized for seizure control in children.

Sodium valporate is a first-line anticonvulsive agent used in epileptic children because of its broad spectrum of activity and tolerability. Weight gain, fatty liver disease, hematological and cardiovascular disorders have been reported as side effects of this widely prescribed medication [1].

Carbamazepine is another drug of choice for seizure control; lipid profile changes; aplastic anemia, nausea and vomiting are among frequent complications of carbamazepine custom in epileptic cases [2].

Total cholesterol (TC) and low-density lipoprotein (LDL) have been identified as risk factors for atherosclerosis along with changes in anatomy and function of great vessels. A previous study suggested that LDL level in childhood is a predictive factor of carotid intima-media thickness (IMT) in young adults and IMT has positive association with chronic heart diseases [3].

The aim of this study was to determine fatty Liver Disease, Carotid IMT and lipid profile in epileptic children who are under treatment.

\section{Materials and Methods}

This prospective study was conducted in Children Medical Center (Affiliated hospital of Tehran University of Medical Sciences) between September 2010 and May 2011 while 38 epileptic children enrolled in this cross-sectional study. Patients who were on carbamazepine or sodium valporate mono-therapy for at least six months were included. Cases 
Table 1. Baseline Characteristics of Patients

\begin{tabular}{lllll}
\hline & $\begin{array}{l}\text { Number of Cases } \\
(\mathbf{\%})\end{array}$ & $\begin{array}{l}\text { Age } \\
(\text { Year })\end{array}$ & $\begin{array}{l}\text { Sex }^{* *} \\
(\mathbf{F} / \mathbf{M})\end{array}$ & $\begin{array}{l}\mathbf{B M I}^{* * *} \\
\left(\mathbf{k g} / \mathbf{m}^{2}\right)\end{array}$ \\
\hline Carbamazepine & $13(34.2 \%)$ & $11 \pm 3.5$ & $3 / 10$ & $22.1 \pm 16.6$ \\
Sodium valporate & $25(65.8 \%)$ & $9 \pm 3.7$ & $5 / 20$ & $17.8 \pm 5.1$ \\
\hline
\end{tabular}

${ }^{*}$ P-value $=0.1 ;{ }^{* *}$ P-value $=0.5 ;{ }^{* * *}$ P-value $=0.2$

who were treated with two or more antiepileptic-drugs or treated less than six months with each of drugs were excluded. Demographic characteristics, height and weight were recorded and body mass index (BMI) calculated; Fasting venous blood sample ( $2 \mathrm{~mL}$ ) drawn from antecubital vein and serum separarted. Autoanalyser by colometric method applied for triglycetides and cholesterol measurements ( ENZOKIT Ranbaxy).

AtouZyme high-density lipoprotein (HDL) cholesterol regent used for HDL determination while LDL calculated by
Freidwald formula: LDL $=$ TC $-(\mathrm{HDL} \times 0.2$ Triglycerides $)$.

Two independent radiology residents performed Bmode ultrasound examinations with a Toshiba Sonolayer SSH160A (Toshiba Medical, Tokyo, Japan) equipped with a $7.5 \mathrm{MHz}$ linear array transducer on subjects in the supine position.

Images of maximum far wall Carotid IMT were recorded at both right and left common carotid arteries. Images were recorded on super-VHS videotapes and read by both independent residents. For each subject the mean IMT was

Table 2. Laboratory Findings of Two Groups

\begin{tabular}{|c|c|c|c|}
\hline & Carbamazepine Group & $\begin{array}{l}\text { Sodium Valporate } \\
\text { Group }\end{array}$ & P-value \\
\hline WBC (White blood cells) & $5715.3 \pm 841.4$ & $7362.4 \pm 2067.2$ & 0.001 \\
\hline RBC (Red blood cells) & $4.8 \pm 0.4$ & $4.5 \pm 0.8$ & 0.3 \\
\hline Hemoglobin (g/dL) & $13.4 \pm 1.7$ & $12.9 \pm 1.2$ & 0.3 \\
\hline Plt (Platelete) & $104328.2 \pm 139881.4$ & $135275.7 \pm 163220$ & 0.5 \\
\hline $\begin{array}{l}\text { ALT (Alanine aminotransferase) } \\
\text { (U/L) }\end{array}$ & $17.9 \pm 10.1$ & $16.9 \pm 7.1$ & 0.7 \\
\hline $\begin{array}{l}\text { AST (Aspartate aminotransferase) } \\
\text { (U/L) }\end{array}$ & $22.4 \pm 7.9$ & $24.7 \pm 6.2$ & 0.3 \\
\hline ALP(Alkaline phosphatase) (U/L) & $591 \pm 130.7$ & $524.6 \pm 244.4$ & 0.5 \\
\hline TG (Triglyceride) (mg/dL) & $71.2 \pm 20.5$ & $80.7 \pm 31.02 \mathrm{~s}$ & 0.2 \\
\hline Total cholesterol (mg/dL) & $156.2 \pm 33$ & $149.4 \pm 24.6$ & 0.3 \\
\hline $\begin{array}{l}\text { HDL (High-density lipoprotein) ( } \\
\text { mg/dL) }\end{array}$ & $53.2 \pm 9.7$ & $54.3 \pm 13.9$ & 0.8 \\
\hline $\begin{array}{l}\text { LDL(Low-density lipoprotein) } \\
\text { (mg/dL) }\end{array}$ & $92.9 \pm 23.1$ & $79 \pm 26.1$ & 0.1 \\
\hline Calcium(mmol/L) & $9.4 \pm 0.6$ & $9.7 \pm 0.4$ & 0.1 \\
\hline Phosphorous (mmol/L) & $5 \pm 0.9$ & $5.4 \pm 1.1$ & 0.9 \\
\hline
\end{tabular}


Table 3. Radiologic Findings of Patients

\begin{tabular}{llll}
\hline & Carbamazepine & Sodium Valproate & P-value \\
\hline Right carotid IMT (mm) & $0.46 \pm 0.09$ & $0.44 \pm 0.06$ & 0.4 \\
Left carotid IMT (mm) & $0.43 \pm 0.07$ & $0.42 \pm 0.06$ & 0.9 \\
$\begin{array}{l}\text { Number of cases with fatty liver } \\
\text { disease }\end{array}$ & 0 & 5 & 0.02 \\
\hline
\end{tabular}

calculated as the average of all mean IMT measurements.

Liver sonography performed by both residents and results were checked for agreement between them for Nonalcoholic Fatty Liver Disease determination. SPSS version 13 (SPSS Inc., Chicago, USA) used for data analysis. Data are presented as mean \pm SDs, frequency and valid percent. Student $t$ test for continuous variables and the Pearson $x^{2}$ test with the Fisher exact test applied for categorical variables assessment. P value less than 0.05 was considered statistically significant.

\section{Results}

Thirty-eight epileptic children participated in this study. Thirteen three were on carbamazepine and 24 were on sodium valproate treatment. Twenty two children in valporic group and three in carbamazepine group presented with generalised tonic-clonic seizure and others (three in valporic group and ten in carbamazepine group) presented with partial seizures. Table 1 shows baseline characteristics of patients. Table 2 shows laboratory findings of two groups presented in mean \pm SDs. Table 3 shows radiologic findings of patients.

Both sonographers detected grade one fatty liver disease in 5 children in sodium valproate group (agreement 100\%).

\section{Discussion}

To our knowledge this is the first study which evaluates liver changes, carotid IMT and lipid profile in epileptic children who are under treatment by sodium valproate or carbamazepine. Sodium valproate is a well-tolerated anti-epileptic drug that has been widely used for epileptic children.

One of its well-established adverse effects is weight gain which leads to nonalcoholic fatty liver disease, insulin resistance and cardiovascular disorders as consequences [4-8].

Our study showed no significant difference of BMI between two groups; however Grosso et al. found that treatment by sodium valproate for at least three months is associated with weight gain in children. In a study by Wirrel et al., they found that $58 \%$ of teenagers who are under treatment with valporic acid get mild to moderate weight gain [9].
We did not observe any differences regarding serum lipid profiles in two groups, which is against findings of Demircioglu et al.. They have found higher total amounts of cholesterol, LDL, TC/HDL in 31 children who were under treatment with carbamazepine than 7 cases who were treated by sodium valproate [10]. By evaluating epileptic children receiving Phenobarbital/sodium valproate/carbamazepine, Eiris et al. reported higher levels of TC, HDL and LDL in children received carbamazepine than other two groups [11].

There were no significant differences in laboratory findings between two groups except in white blood cell count (WBC), which was significantly lower in carbamazepine group. Aplastic anemia is regarded as a considerable adverse effect of carbamazepine; hence all cases who are treated with this medication should be evaluated regularly by CBC test [2]. Although there are studies that reported thrombocytopenia as a main adverse effect of valporic acid [12]; in this study PLT level was higher is valporic than carbamazepine group.

In the current study five cases in sodium valproate group had fatty liver disease in liver sonographic assessment while there was no evidence of this finding in carbamazepine group. Non-alcoholic fatty liver has a wide spectrum from simple steatosis to non-alcoholic steatohepatitis with necroinflammation and fibrosis that may progress to cirrhosis an unreversible liver damages.

Valproate and its metabolites interfere with mitochondrial function and fatty acid oxidation which result in induction of micro vesicular hepatic steatosis. This has been believed as the mechanism of fatty liver development in cases treated with sodium valproate [13].

In a previous study, Luefa et al. reported fatty liver in $60.9 \%$ of patient under Valproate treatment while this figure was $22.7 \%$ in patients under carbamazepine; higher lipid profile level was reported in carbamazepine group [14].

We found no statistically significant difference between carotid IMTs in two groups while in a study by Erdemir A et al. they found increased intima media thickness of common carotid arteries in children under sodium valproate therapy in comparison with healthy ones [15]. Intima media thickness is a simple, quick, non invasive and cost-effective method that that can show atherosclerosis in middle-aged and older adults. It has positive association with chronic heart diseases 
[3].

Our study includes some limitations. First of all, our sample size was small because Children Medical Center is the main referral center for children care in Iran and most patients who refer to this center are cases with refractory seizure under treatment with multi-drug anti-epileptic regimen. Second, our study lacked a comparison with healthy group due to ethical issues such as blood sampling in healthy individuals and the fact that parents in our culture are so strict to let their healthy children to be entered in studies with no gain for them.

To come to a conclusion we cannot define anything about carbamazepine lipid profile changes while we may suggest that children who are treated with sodium valproate would be better to be carefully assessed by sonographic modalities for developing fatty liver as an adverse effect of the drug.

\section{References}

1. Guerrini R. Valproate as a mainstay of therapy for pediatric epilepsy. Paediatr Drugs. 2006;8(2):113-129.

2. Gayford JJ, Redpath TH. The side-effects of carbamazepine. Proc R Soc Med. 1969;62(6):615-616.

3. Poli A, Tremoli E, Colombo A, Sirtori M, Pignoli P, Paoletti R. Ultrasonographic measurement of the common carotid artery wall thickness in hypercholesterolemic patients. A new model for the quantitation and follow-up of preclinical atherosclerosis in living human subjects. Atherosclerosis. 1988;70(3):253-261.

4. Luef GJ, Waldmann M, Sturm W, Naser A, Trinka E, Unterberger I, Bauer G, et al. Valproate therapy and nonalcoholic fatty liver disease. Ann Neurol. 2004;55(5):729732.

5. Isojarvi JI, Laatikainen TJ, Knip M, Pakarinen AJ, Juntunen KT, Myllyla VV. Obesity and endocrine disorders in women taking valproate for epilepsy. Ann Neurol. 1996;39(5):579-584.

6. Pylvanen V, Knip M, Pakarinen A, Kotila M, Turkka J, Isojarvi JI. Serum insulin and leptin levels in valproateassociated obesity. Epilepsia. 2002;43(5):514-517.

7. Pylvanen V, Pakarinen A, Knip M, Isojarvi J. Insulin-related metabolic changes during treatment with valproate in patients with epilepsy. Epilepsy Behav. 2006;8(3):643-648.

8. Pi-Sunyer FX. Medical hazards of obesity. Ann Intern Med. 1993;119(7 Pt 2):655-660.

9. Wirrell EC. Valproic acid-associated weight gain in older children and teens with epilepsy. Pediatr Neurol. 2003;28(2):126-129.

10. Demircioglu S, Soylu A, Dirik E. Carbamazepine and valproic acid: effects on the serum lipids and liver functions in children. Pediatr Neurol. 2000;23(2):142-146.

11. Eiris J, Novo-Rodriguez MI, Del Rio M, Meseguer P, Del Rio MC, Castro-Gago M. The effects on lipid and apolipoprotein serum levels of long-term carbamazepine, valproic acid and phenobarbital therapy in children with epilepsy. Epilepsy Res. 2000;41(1):1-7.

12. Chateauvieux S, Morceau F, Dicato M, Diederich M. Molecular and therapeutic potential and toxicity of valproic acid. J Biomed Biotechnol. 2010;2010.

13. Glasgow AM, Chase HP. Production of the features of Reye's syndrome in rats with 4-pentenoic acid. Pediatr Res. 1975;9(3):133-138.

14. Luef G, Rauchenzauner M, Waldmann M, Sturm W, Sandhofer A, Seppi K, Trinka E, et al. Non-alcoholic fatty liver disease (NAFLD), insulin resistance and lipid profile in antiepileptic drug treatment. Epilepsy Res. 2009;86(1):42-47.

15. Erdemir A, Cullu N, Yis U, Demircioglu F, Kir M, Cakmakci H, Unal N, et al. Evaluation of serum lipids and carotid artery intima media thickness in epileptic children treated with valproic acid. Brain Dev. 2009;31(10):713-716. 